\title{
Light absorption by organic carbon from wood combustion
}

\author{
Y. Chen and T. C. Bond \\ University of Illinois, Champaign-Urbana, IL, USA \\ Received: 4 September 2009 - Published in Atmos. Chem. Phys. Discuss.: 30 September 2009 \\ Revised: 20 January 2010 - Accepted: 26 January 2010 - Published: 16 February 2010
}

\begin{abstract}
Carbonaceous aerosols affect the radiative balance of the Earth by absorbing and scattering light. While black carbon (BC) is highly absorbing, some organic carbon (OC) also has significant absorption, especially at near-ultraviolet and blue wavelengths. To the extent that $\mathrm{OC}$ absorbs visible light, it may be a non-negligible contributor to positive direct aerosol radiative forcing. Quantification of that absorption is necessary so that radiative-transfer models can evaluate the net radiative effect of OC.

In this work, we examine absorption by primary OC emitted from solid fuel pyrolysis. We provide absorption spectra of this material, which can be related to the imaginary refractive index. This material has polar character but is not fully water-soluble: more than $92 \%$ was extractable by methanol or acetone, compared with $73 \%$ for water and 52\% for hexane. Water-soluble OC contributes to light absorption at both ultraviolet and visible wavelengths. However, a larger portion of the absorption comes from OC that is extractable only by methanol. Absorption spectra of water-soluble OC are similar to literature reports. We compare spectra for material generated with different wood type, wood size and pyrolysis temperature. Higher wood temperature is the main factor creating $\mathrm{OC}$ with higher absorption; changing wood temperature from a devolatilizing state of $210^{\circ} \mathrm{C}$ to a near-flaming state of $360^{\circ} \mathrm{C}$ causes about a factor of four increase in massnormalized absorption at visible wavelengths. A clear-sky radiative transfer model suggests that, despite the absorption, both high-temperature and low-temperature OC result in negative top-of-atmosphere radiative forcing over a surface with an albedo of 0.19 and positive radiative forcing over bright surfaces. Unless absorption by real ambient aerosol is higher than that measured here, it probably affects global average clear-sky forcing very little, but could be important in energy balances over bright surfaces.
\end{abstract}

Correspondence to: T. C. Bond (yark@uiuc.edu)

\section{Introduction}

Aerosol particles can directly modify the earth's radiation balance by absorbing and scattering solar radiation, and this is one of the largest uncertainties in the radiative forcing of climate (Anderson et al., 2003, McComiskey et al., 2008; IPCC, 2007). Absorption of light, a component of light extinction, is special in two ways. First, it causes warming of the entire Earth system and atmospheric heating, whereas scattering - the other larger component of extinction - causes cooling. Second, only a few types of aerosols, specifically carbonaceous particles and mineral dust, absorb solar radiation. Carbonaceous aerosols are prevalent in urban areas (Molnár et al., 1999; He et al., 2001; Johnson et al., 2006; Meng et al., 2007; Krecl et al., 2007) and in continental outflow (Gabriel et al., 2002; Mader et al., 2002; Quinn and Bates, 2005). Carbonaceous aerosol is composed of black carbon $(\mathrm{BC})$ and various types of organic carbon (OC). By mass, OC is 3-12 times more than BC (Molnár et al., 1999; Husain et al., 2007), and it accounts for 10-70\% of total fine aerosol mass (Murphy et al., 2006; Quinn and Bates, 2003; Turpin et. al., 2000).

Visible light absorption is important for direct radiative forcing, since $47 \%$ of solar energy is distributed within visible range between $400 \mathrm{~nm}$ and $700 \mathrm{~nm}$. Absorption in the ultraviolet range is also significant, since it may affect photochemistry and thus reduce tropospheric ozone concentration (Jacobson, 1998). Because BC is known to be the most absorbing aerosol in the visible wavelengths in the atmosphere, the optical properties of $\mathrm{BC}$ have been the focus of much investigation.

In recent years OC has been reported to be a nonnegligible contributor to aerosol light absorption, particularly in the ultraviolet and shorter-wavelength blue regions. Much of this absorbing OC has been associated with solid-fuel burning. Bond (2001) reported a strong spectral dependence of absorption by carbonaceous particles from coal combustion, and proposed that might result from organic components

Published by Copernicus Publications on behalf of the European Geosciences Union. 
rather than black carbon. Kirchstetter et al. (2004) measured near UV and visible light absorption of filter-based aerosol samples from biomass burning before and after acetone treatment, and estimated $50 \%$ of the total light absorption was contributed by organic carbon. Qin and Mitchell (2009) suggested that the variable blue-band absorption of Australian aerosols may be related to organic compounds emitted during certain vegetation burning. Roden et al. (2006) also discussed absorption with strong wavelength dependence from smoldering biofuel. Pöschl (2003) suggested that the molecular structure of the light absorbing organic aerosols were similar to polycyclic aromatic hydrocarbons (PAHs), humiclike substances (HULIS) and biopolymers. Andreae and Gelencsér (2006) reviewed the evidence for and nature of this "brown carbon." Sun et al. (2007) examined 200 organic compounds and inferred that the light absorbing organic carbon was probably oxygenated or multifunctional, or had very high molecular weight. This work also compared reported values of absorption by organic carbon, and found that organic carbon from combustion sources might be five times more absorbing than water-soluble OC (Havers et al., 1998; Varga et al., 2001; Hoffer et al., 2006). They suggested that the compounds not extractable by water or alkali must contribute to this kind of difference. Bergstrom et al. (2007) reported strong wavelength dependence in biomass-burning regions.

Although OC could have an important contribution to radiative forcing, its treatment in global climate models to date has been simplistic; it has been treated as a compound that primarily scatters light and has invariant properties (Liousse et al, 1996; Cooke et al, 1999; Chung and Seinfeld, 2002). In fact, chemical and optical properties of OC may differ due to the nature of the OC source or atmospheric processing. The present paper aims to contribute to understanding this variability by examining biomass combustion, one of the largest sources for primary BC and OC. Bond et al. (2004) estimated the global annual emissions of $\mathrm{BC}$ and primary $\mathrm{OC}$ as $8 \mathrm{Tg}$ and $34 \mathrm{Tg}$ respectively. Of the total primary $\mathrm{OC}$, the contribution of biofuel and open biomass burning were $19 \%$ and $74 \%$ respectively.

Emission rates and chemical properties from biomass burning are quite variable (e.g. Reid et al., 2005). One method of attempting to capture this variability is to examine a wide range of fuels (e.g. Andreae et al., 1998; Ferek et al., 1998; Schauer et al., 2001). However, we have observed large variability even when wood of similar composition is burned (Roden et al., 2009), suggesting that other variables such as fuel size or combustion conditions must also affect emissions. In fact, models of wood pyrolysis and char production (e.g. Shafizadeh, 1982; Antal and Varhegyi, 1995; Bryden et al., 2002) are largely able to model reaction products for different types of biomass with simple kinetic parameters, although they admit large variation in the composition of the escaping volatile matter which forms OC. This success suggests that the factors governing emissions are partly thermodynamic and kinetic, and not strictly attributable to wood type. It is impossible to measure OC properties - or at least, to obtain funding for such broad measurements - for every type of wood in every form of combustion around the world. Furthermore, even if such an array of measurements was feasible, the detail could not be applied in an emission model. However, if the variables controlling these properties are isolated, they can be used to understand and predict emissions from a wide variety of wood types and combustion conditions. Therefore, our approach in this work is to examine OC emitted from highly controlled thermal degradation of biomass. These can then be connected with realworld variables such as combustion temperature, fuel type and fuel size. We recognize that this is an ambitious target, and that the present contribution is only a small step toward it. Since the vast majority of primary organic aerosol arises from biomass combustion, we believe that such a systematic approach is warranted. Wood combustion comprises at least two distinct processes that affect the properties of the resulting aerosol: release of volatile material from the solid, and its condensation or combustion in the atmosphere. In a real burn, after this material leaves the solid wood, it may either condense to form "organic carbon" or burn in a diffusion flame to produce black carbon. Our goal in this experiment is to understand the nature of the devolatilizing material generated by wood pyrolysis. This material is emitted directly.

The present work describes a procedure including generation, extraction and analysis of organic carbon from wood pyrolysis, the first step in combustion of solid fuel. We present optical properties of organic carbon generated at different conditions and wood sizes. Preliminary experiments had indicated that wood size affected emission rates and particle properties. Heat transfer into the wood is most rapid into the shortest dimension, but mass transfer of the volatile material out of the wood occurs along the wood grain - the longer dimension - until cracks form in the wood. Thus, volatile material can be held at a high temperature for a long time. This situation is similar to observations of wood used for cooking (Roden et al., 2006), where white smoke escaped mainly from the end of the fuel. We employed UV-vis spectrophotometry to measure the light absorption of liquid extracts of aerosol samples, although this method measures the bulk liquid refractive index and not particulate absorption. Absorption of bulk liquid extracts can be used to derive the imaginary refractive index, a necessary input to the Mie theory used to model absorption and scattering in radiativetransfer models. Using organic solvents and water to extract OC provides understanding of the nature of organic carbon, including its water-solubility. The absorption spectra of OC in bulk liquid extracts show that a large fraction of light absorption in the near-UV and visible range is caused by waterinsoluble organic carbon with some polar component. 


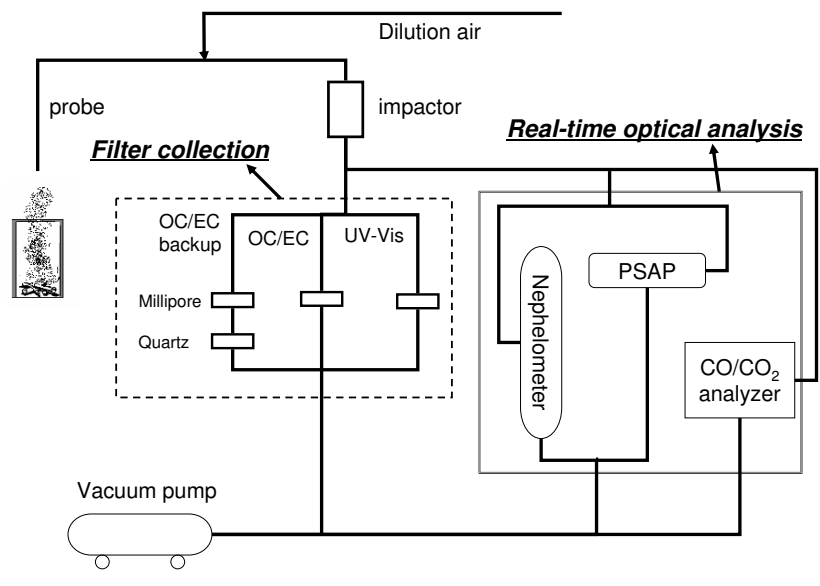

Fig. 1. Schematic of sampling system.

\section{Methods}

\subsection{Sample generation}

OC samples were generated in a series of controlled pyrolysis experiments and then collected on quartz filters. Figure 1 shows the schematic of the sampling system. Organic carbon samples were generated in the laboratory by pyrolyzing small pieces of wood in an adjustable, electrically-heated combustor. The combustor, shown in Fig. 2, created a temperaturecontrolled environment using a 120 volt, 650 watt, Watlow VC403A06A, resistive heating cylinder sealed to a base of insulating firebricks. The combustor contains no flame source and formation of black carbon can be avoided by preventing flames if no oxygen enters the combustor. The top was enclosed and a nitrogen carrier gas kept the combustor at a slight positive pressure. Smoke escaped through a chimney (not shown) and was sampled as described below. Our combustor simulates the release of volatile matter at realistic wood temperatures; there is no oxygen either inside the wood or in the diffusion flame.

Wood pieces were placed in the bottom center of the combustor, and temperature was measured near the exterior of the wood pieces. After an initial natural dilution that entrained room-temperature air until the temperature reached $70^{\circ} \mathrm{C}$, a diluting probe further diluted the smoke stream with HEPAfiltered air at a ratio of $4: 1$ to cool the emissions to ambient temperature $\left(25^{\circ} \mathrm{C}\right)$. Particles larger than $1 \mu \mathrm{m}$ were removed with an impactor. A change of dilution ratio from 4:1 to 40:1 did not change the measured absorption per mass (i.e., the difference was within experimental uncertainty). Other effects of gas-particle partitioning are discussed in Sect. 2.5.2.

We used two types of wood (oak and pine) of three different sizes. These will be reported as cross-sectional area (height $\times$ width) times along-grain length. "Small" wood was $(0.64 \mathrm{~cm} \times 1.92 \mathrm{~cm}) \times 1.92 \mathrm{~cm}$. "Medium" wood was $(1.92 \mathrm{~cm} \times 1.92 \mathrm{~cm}) \times 1.92 \mathrm{~cm}$. "Large" wood had the same

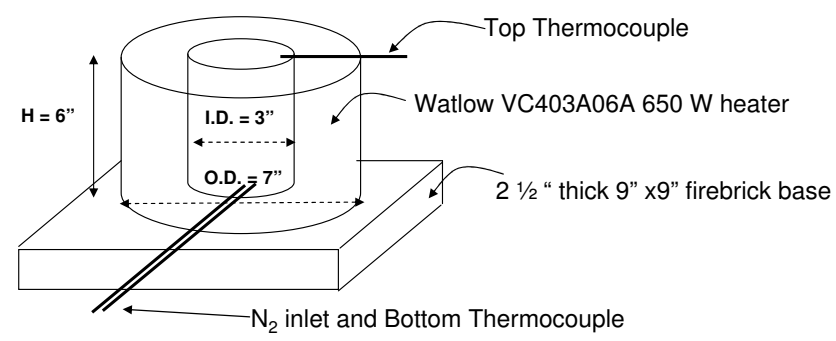

Fig. 2. Detailed Diagram of Combustor.

cross-section as medium wood $(1.92 \mathrm{~cm} \times 1.92 \mathrm{~cm})$, but its length was $5.76 \mathrm{~cm}$. These three wood sizes will be indicated by $\mathrm{S}, \mathrm{M}$ and $\mathrm{L}$ respectively. In all cases, the wood moisture was very low (about 10\%). We refer to samples using the format "type_size_temperature" (e.g. oak_M_270). In total, 18 complete experiments and analyses were carried out with differing generation temperatures $\left(210 \pm 20^{\circ} \mathrm{C}, 270 \pm 20^{\circ} \mathrm{C}\right.$ and $360 \pm 20^{\circ} \mathrm{C}$ ), wood types and wood sizes, as listed in Table 1 . Additional experiments to elucidate the nature of the samples will also be described later.

\subsection{Sample collection}

We collected simultaneous samples on filters in three branches. Unless stated otherwise, all filters were quartz (Pall, TISSUQUARTZ 2500QAT-UP) and filter holders were URG (URG-2000-30RAF). The first branch was used to collect samples for UV-vis absorption, which required large samples (milligram quantities). The resulting filter loading is higher than the range of the analyzer used for total carbon, so a second branch had a smaller flow rate for this analysis. However, quartz filters may also collect adsorbed organic vapors (McDow and Huntzicker, 1990; Turpin et al., 1994). A Teflon-quartz filter combination has been recommended to estimate this artifact (Turpin et al., 1994; Kirchstetter et al., 2001), with a Teflon filter (Millipore, Fluoropore ${ }^{\mathrm{TM}}$ Membrane Filters, FALP04700) removing particles from the gas stream, and a quartz filter estimating the gaseous adsorption. The third branch contained this combination.

Quartz filters for collection were baked at $550^{\circ} \mathrm{C}$ in air in a muffle furnace for at least four hours and stored in Petri dishes lined with baked aluminum foil prior to sampling. At the end of the sampling period, the filters were returned to the dishes immediately and stored in a freezer until analysis. One blank filter for each preparation batch underwent the same OC/EC and UV-vis absorption analysis as the analytical filters. 
Table 1. Overview of sample information and $\AA_{\text {ap }}$ (whole investigated range, UV range and visible range).

\begin{tabular}{llllllll}
\hline Wood type & Wood size & $\begin{array}{l}\text { Temperature } \\
\left({ }^{\circ} \mathrm{C}\right)\end{array}$ & Whole range & $\begin{array}{l}\AA_{\text {ap }} \text { of methanol extracts } \\
\text { UV range } \\
(-400 \mathrm{~nm})\end{array}$ & $\begin{array}{l}\text { Visible } \\
(400 \mathrm{~nm}-)\end{array}$ & $\begin{array}{l}\AA_{\text {ap }} \text { of } \\
\text { water extracts }\end{array}$ & $\begin{array}{l}\alpha / \rho \text { methanol } \\
\text { extract }(400 \mathrm{~nm})\end{array}$ \\
& & & & & & \\
\hline pine & $\mathrm{M}$ & 210 & 10.9 & 11.8 & 10.7 & 14.8 & 1300 \\
oak & $\mathrm{M}$ & 210 & 10.1 & 13.3 & 9.7 & 14.5 & 2000 \\
pine & $\mathrm{L}$ & 210 & 11.4 & 14.3 & 9.5 & 17.8 & 3500 \\
oak & $\mathrm{L}$ & 210 & 10.0 & 12.2 & 8.5 & 16.8 & 4500 \\
pine & $\mathrm{S}$ & 270 & 9.5 & 10.7 & 9.4 & 14.4 & 4000 \\
oak & $\mathrm{S}$ & 270 & 9.1 & 12.0 & 8.9 & 15.2 & 4300 \\
pine & $\mathrm{M}$ & 270 & 8.8 & 9.8 & 8.8 & 15.6 & 4000 \\
oak & $\mathrm{M}$ & 270 & 8.2 & 9.5 & 8.1 & 15.2 & 6600 \\
oak & $\mathrm{M}$ & 270 & 8.1 & 9.6 & 7.8 & 13.9 & 6300 \\
oak & $\mathrm{M}$ & 270 & 8.1 & 9.2 & 8.0 & 12.4 & 7400 \\
oak & $\mathrm{M}$ & 270 & 8.7 & 8.7 & 7.9 & 9.4 & 6700 \\
pine & $\mathrm{L}$ & 270 & 9.5 & 11.5 & 9.0 & 16.4 & 3500 \\
oak & $\mathrm{L}$ & 270 & 8.1 & 9.4 & 7.8 & 15.8 & 6000 \\
pine & $\mathrm{M}$ & 360 & 7.8 & 7.9 & 7.8 & 9.4 & 8800 \\
oak & $\mathrm{M}$ & 360 & 6.9 & 6.6 & 7.6 & 8.6 & 10400 \\
oak & $\mathrm{L}$ & 360 & 7.5 & 7.5 & 7.8 & 9.7 & 10100 \\
pine & $\mathrm{L}$ & 360 & 7.5 & 7.3 & 8.4 & 9.4 & 10600 \\
oak & $\mathrm{L}$ & 360 & 7.1 & 6.9 & 7.8 & 8.8 & 9700 \\
\hline
\end{tabular}

\subsection{Analytical techniques}

Quartz filters in the higher flow rate branch were extracted with deionized water and organic solvents, methanol (Fisher Scientific, A.C.S. certified), hexane (Fluka, puriss, p.a.) and acetone (Fisher Scientific, A.C.S. certified). A punch of filter and solvent were sonicated (Ultrasonic Cleaner, Cole Parmer 8892 ) for $1 \mathrm{~h}$, kept at room temperature for $20 \mathrm{~h}$ to let the solution reach equilibrium, and sonicated for 1 additional hour. Polidori et al. (2008) reported that sonicating increased extraction efficiencies by $10-15 \%$. All extracts were filtered by syringe through a $25 \mathrm{~mm}$ diameter filter with a $0.2 \mu \mathrm{m}$ pore size (Whatman, Anotop* Disposable Syringe Filters) to remove impurities during the extraction process. However, some particles carried by the solvent may be retained by the filter during the filtration step, and our method of determining $\alpha / \rho$ would underestimate its magnitude. Further investigation of carbon loss in the filtration step is required to account for this bias. Residual filters were taken out of the solutions, dried in a fume hood and then kept in the freezer in dishes prepared as described previously. Contamination during drying was less than $1 \%$ of the collected OC, as determined by extracting and drying blank quartz filters with the same procedure.

Light absorption of extracts was measured at wavelengths from $190 \mathrm{~nm}$ to $800 \mathrm{~nm}$ with UV-vis recording spectrophotometer (Shimadzu, UV-2401). Each spectrum was determined relative to a reference cuvette which contained the same solvent. Four considerations determined the valid spec- tral range: (1) Contamination from Whatman filters affected absorption when wavelength was shorter than $300 \mathrm{~nm}$ (tested with extracts of blank filters); (2) acetone has very high absorbance at wavelengths shorter than $340 \mathrm{~nm}$, so no sample absorbance can be determined for those extracts at short wavelengths; (3) the instrument detection limit was $A=0.05$; we mark this range of validity in all results; and (4) we did not use data where Beer-Lambert law is not valid. Dilution tests ranging from 12:1 to $2: 1$ confirmed that the Beer-Lambert law was valid for these samples in the range $A<1$. This absorbance usually corresponds to wavelengths between $300-390 \mathrm{~nm}$. Based on these considerations, the typical valid range differs for samples and solvent extracts, beginning at $300-400 \mathrm{~nm}$ and ending at $450-550 \mathrm{~nm}$. The difference in valid ranges means that absorption data will not be provided for exactly the same wavelength range for all samples. In some cases, there is only a narrow overlap. In this paper, we will focus on the spectrometer data from $360 \mathrm{~nm}$ to $500 \mathrm{~nm}$; spectra between $500 \mathrm{~nm}$ and $600 \mathrm{~nm}$ will also be presented even though the data are often below detection limit. In the figures, we will cut off at the shorter wavelength side for values of $A$ greater than 1 and the results at longer wavelength side below instrument detection limit were indicated by dashed lines.

Our procedure may yield inaccurate results if very concentrated material has different absorbing properties than diluted material, and this possibility should be investigated in future work. 


\subsection{Data reduction: absorption per mass}

The main values reported in this paper are absorption crosssection divided by organic carbon density $\alpha / \rho$ in the unit of $\mathrm{cm}^{2} / \mathrm{g}$. Here $\alpha$ is the absorption coefficient, and $\rho$ is the density of the dissolved compounds. The value of $\alpha / \rho$ can be derived from spectroscopic data, using the sample absorbance A, the optical path length $\mathrm{L}(\mathrm{cm})$, and the concentration of liquid solution $c(\mathrm{~g} / \mathrm{L})$, as shown in Eq. (1).

$\alpha / \rho=\frac{A}{c \cdot L} \cdot \ln (10)$

Here, $A$ (absorbance) comes from the spectrophotometer, $L$ is $1 \mathrm{~cm}$, and the concentration $c$ was calculated from carbon in extracts divided by the extract volume.

Sun et al. (2007) pointed out that $\alpha / \rho$ is easily derived from measured spectra, and also easy to translate to radiativetransfer models. The absorption cross-section per mass for particulate matter must be determined using Mie theory combined with a refractive index. The imaginary part $k$ of refractive index $m=n+k i$ is proportional to $\alpha: \alpha=4 \pi k / \lambda$. A density must be chosen to obtain an imaginary refractive index from $\alpha / \rho$. That density is somewhat uncertain, but it is only an intermediate value; it is required again in Mie or other models that calculate particulate absorption per mass. If the same density is used in both calculations, it has little effect on particulate absorption. We therefore choose to communicate in terms of $\alpha / \rho$. Although the units are the same as those of mass-normalized absorption cross-section by particulate matter, the two differ and should not be confused.

\subsection{Determination of carbon in extracts}

The total carbon in each aliquot before and after extraction was measured with a thermal-optical OC/EC analyzer (Sunset Laboratory, Tigard, OR), for both the high and low flow rate filters. $\mathrm{OC}$ in the extracts was calculated by subtracting $\mathrm{OC}$ in the residual filter from $\mathrm{OC}$ in the filter before extraction. Total carbon analyzers typically used for water quality were inappropriate because of the organic solvents.

In many cases, the loading on the high-flow filters before extraction was above the valid range of the OC/EC analyzer. In such cases, the total OC before extraction on these filters was determined using the low-flow filter and the ratio of the high and low flows.

Emissions from primary combustion sources contain organic matter with a broad range of volatility (Schauer et al., 2001; Shrivastava et al., 2006). Organic carbon collected on quartz filters contains three broad classes: nonvolatile particulate carbon, semi-volatile particulate carbon that would partition to the gas phase at lower concentrations, and gaseous carbon adsorbed to the quartz filters. Each class might have very different light absorption, and separating them before analysis would be advisable. Such separation is difficult to combine with light absorption measurements, which require large samples. As we will show, visible light absorption in our samples is largely attributable to nonvolatile organic carbon, and our final results provide values for this carbon. In the following sections, we describe how we account for the other two types of carbon.

Values of $\alpha / \rho$ are underestimated if we do not account for semi-volatile and gaseous carbon. However, the underestimates are in the same direction for all samples, and will affect absolute magnitudes but not comparisons. During the first portion of the discussion of results, we compare properties of all collected carbon. Later, when providing absorption for use in models, we adjust $\alpha / \rho$ so that the values reflect only non-volatile organic carbon.

\subsubsection{Adsorbed gaseous carbon}

Two methods of estimating gaseous carbon adsorbed to the high-flow filter are possible.

1. We assume that the amount of organic vapors adsorbed on the quartz filter is constant regardless of flow rate. This would be true if the adsorption sites were saturated. The adsorbed vapor would be the same as on the lowflow backup filter, and Eq. (2) gives total carbon. This method gives a lower bound for the OC loading on the high-flow filters.

$$
C_{\text {before extraction }}=C_{\mathrm{HF}}=\left(C_{\mathrm{LF}}-C_{\mathrm{LFbackup}}\right) \frac{Q_{\mathrm{HF}}}{Q_{\mathrm{LF}}}+C_{\mathrm{LFbackup}}
$$

2. We assume that the quantity of adsorbed organic vapors is proportional to the flow rate, and can be estimated by multiplying the low-flow backup filter by the ratio of the flow rates. Total carbon is then given by Eq. (3). This estimate gives an upper bound for the OC loading.

$$
C_{\text {before extraction }}=C_{\mathrm{HF}}=C_{\mathrm{LF}} \cdot \frac{Q_{\mathrm{HF}}}{Q_{\mathrm{LF}}}
$$

Estimates of gaseous OC calculated by these two methods differ by $30 \pm 18 \%$. In this paper, we use the first estimation method, so the particulate OC may be underestimated and the calculation may overestimate absorption per mass of extracts by about $15 \%$. However, the overestimates are in the same direction for all samples; this will affect the absolute magnitude of absorption, but not the comparison between extracts.

\subsubsection{Semi-volatile organic carbon (SVOC)}

Sampled aerosol components may differ from those found in the particle phase in ambient air if the concentration and temperature differ at sampling, which they often do. Semivolatile organic carbon partitions to either the particle phase or the gaseous phase depending on concentrations and temperatures. Furthermore SVOC can produce a substantial part of secondary organic aerosols (Robinson et al., 2007). Due to the physical and chemical characteristics of SVOC, it needs 

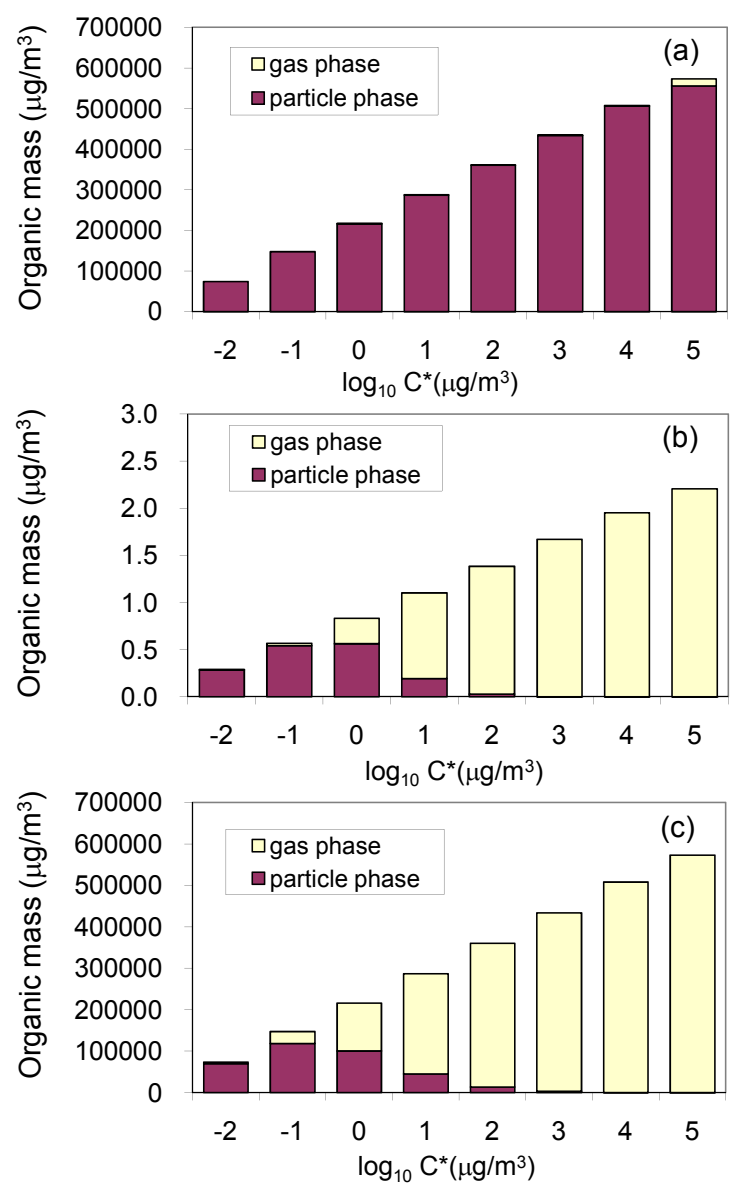

Fig. 3. SVOC partitioning. (a) Partitioning of original SVOC from wood combustion after $4: 1$ dilution $\left(2.6 \times 10^{6} \mu \mathrm{g} / \mathrm{m}^{3}, 298 \mathrm{~K}\right)$; (b) Partitioning of SVOC with the same volatility profile under ambient conditions $\left(10 \mu \mathrm{g} / \mathrm{m}^{3}, 298 \mathrm{~K}\right)$; (c) Partitioning of SVOC with the same volatility profile $\left(2.6 \times 10^{6} \mu \mathrm{g} / \mathrm{m}^{3}, 443 \mathrm{~K}\right)$.

to be treated separately in models. When providing quantitative absorption for radiative transfer models, we will be mainly focusing on the absorption caused by non-volatile organic carbon (NVOC). We must remove the contribution of SVOC from both absorbance and carbon mass, to obtain the absorption per mass of carbon by NVOC. We will discuss how we estimate the contribution of SVOC and NVOC in this section.

We use the volatility distribution model proposed in Donahue et al. (2006) in our evaluation of OC. The critical variable in the model is the saturation concentration $C^{*}$ representing the partitioning of $\mathrm{OC}$ in both particle phase and gaseous phase. We consider SVOC distribution with $\log$ spaced $C^{*}$ ranging from $0.01 \mu \mathrm{g} / \mathrm{m}^{3}$ to $100000 \mu \mathrm{g} / \mathrm{m}^{3}$ at $300 \mathrm{~K}$.

The fraction of compound $i$ found in the particle phase can be described by partitioning coefficient, given an effective saturation concentration.
$\xi_{i}=\left(1+\frac{C_{i}^{*}}{C_{\mathrm{OA}}}\right)^{-1} ; \quad C_{\mathrm{OA}}=\sum_{i} C_{i} \xi_{i}$

Where $C_{i}$ is the organic compounds concentration in all phases, $C_{\mathrm{OA}}$ is the total mass concentration of organic aerosol.

Based on an averaged OC loading around $200 \mu \mathrm{g} / \mathrm{cm}^{2}$ on the quartz filter, with a thickness of $1 \mathrm{~mm}$ and OM/OC ratio of 1.3 , we roughly estimate the concentration of fresh organic carbon on the filter as $2.6 \times 10^{6} \mu \mathrm{g} / \mathrm{m}^{3}$. The theoretical partitioning of $\mathrm{OC}$ to the gas phase and particle phase under these conditions is shown in Fig. 3a.

If the material were diluted to achieve ambient conditions, with a total OC concentration around $10 \mu \mathrm{g} / \mathrm{m}^{3}$, the partitioning of SVOCs in the two phases would be that in Fig. 3b.

As compounds are warmed, the equilibrium shifts. The saturation concentration for each log-spaced bin at an elevated temperature $T_{2}$ can be related to that at $300 \mathrm{~K}$ (sampling conditions) based on the Clausius-Clapeyron Equation.

$C_{i}^{*}\left(T_{2}\right)=C_{i}^{*}(300 \mathrm{~K}) \cdot \exp \left[\frac{\Delta H_{v}}{R}\left(\frac{1}{300 \mathrm{~K}}-\frac{1}{T_{2}}\right)\right]$

According to Donahue et al. (2006), we assume an $\Delta H_{v}$ for the compounds with saturation concentration of $1 \mu \mathrm{g} / \mathrm{m}^{3}$ as $100 \mathrm{~kJ} / \mathrm{mole}$, the factor of 10 spacing in saturation concentration corresponds to a succession of enthalpies ( $\Delta H_{\mathrm{vap}}$ ) separated by $5.8 \mathrm{~kJ} / \mathrm{mole}$.

Figure $3 \mathrm{c}$ shows the equilibrium partitioning of $\mathrm{OC}$ on the filter at filter concentration and $443 \mathrm{~K}$. In order to compare with the original ambient temperature, the $\mathrm{x}$-axis is still the $C^{*}$ at $300 \mathrm{~K}$, not at $443 \mathrm{~K}$. The partitioning distribution under $443 \mathrm{~K}$ at filter concentration is comparable with that under ambient conditions and low concentrations.

\subsection{Repeatability}

Repeatability was examined in two ways: first, by repeating extraction and measurements using two punches from one sampled filter, and second, by using two punches from two different filters collected at the same pyrolysis condition. Tests using the same filter showed that the absorption per mass was reproducible within $1.1 \%$ for methanol extract and 3.5\% for water extract. Sample generation was repeated for medium size oak wood at $270^{\circ} \mathrm{C}$ and $360^{\circ} \mathrm{C}$, at the valid wavelength range, the resulting value of absorption per carbon differed by $13 \pm 3 \%$ for methanol extract, $5 \pm 5 \%$ for water extract for oak $\_$M $\_270$, and $5 \pm 1 \%$ for methanol extract, $8 \pm 3 \%$ for water extract for oak_M_360. Since we will mainly focus on methanol and water extracts, as discussed in Sect. 3.1, acetone and hexane extracts were not tested for repeatability. 


\subsection{Determination of absorption Ångström exponent $\left(\AA_{\text {ap }}\right)$}

Absorption Ångström exponent is a measure of the spectral dependence of aerosol light absorption, which is required for extrapolation of absorption coefficients that are obtained at a limited range of wavelengths. Sun et al. (2007) proposed band-gap and Urbach relationships to explain wavelength dependence. We believe those are more physical, but the atmospheric community is more familiar with $\AA_{\text {ap }}$, and we use that measure here. It is defined as:

$\AA_{\mathrm{ap}}=\frac{-\ln \left(\alpha\left(\lambda_{1}\right) / \alpha\left(\lambda_{2}\right)\right)}{\ln \left(\lambda_{1} / \lambda_{2}\right)}$

In this work, we determined $\AA_{\text {ap }}$ with a linear regression of $\ln (\alpha / \rho)$ against $\ln (\lambda)$ through the valid wavelength range for each sample $(0.02<A<1$ and $\lambda>300 \mathrm{~nm})$.

\subsection{Radiative impact}

We use a variant of "simple forcing efficiency" defined by Bond and Bergstrom (2006) to provide a first estimate of the climatic impact of these particles. This value was originally a manipulation of the Chylek and Wong (1995) equation that normalizes impact by particle mass. A wavelengthdependent version that can be integrated to produce total forcing is:

$$
\begin{aligned}
& \frac{\mathrm{dSFE}}{d \lambda}=-\frac{1}{4} \frac{d S(\lambda)}{d \lambda} \tau_{\mathrm{atm}}^{2}(\lambda)\left(1-F_{c}\right) \\
& {\left[2\left(1-a_{s}\right)^{2} \beta(\lambda) \cdot \operatorname{MSC}(\lambda)-4 a_{s} \cdot \operatorname{MAC}(\lambda)\right]}
\end{aligned}
$$

where SFE is the simple forcing efficiency $(\mathrm{W} / \mathrm{g}), d S(\lambda) / d \lambda$ is the solar irradiance, $\tau_{\text {atm }}$ is the atmospheric transmission (0.79), $F_{c}$ is the cloud fraction (0.6), $a$ is the surface albedo (average 0.19), $\beta$ is the backscatter fraction, and MSC and MAC are the mass scattering and absorption cross sections per gram, respectively. Wavelength-dependent atmospheric transmission comes from the ASTM G173-03 Reference Spectra.

Using the imaginary refractive indices derived in this paper, along with a fixed real refractive index of 1.55 , we performed Mie calculations every $5 \mathrm{~nm}$ between 300 and $950 \mathrm{~nm}$ to provide mass scattering and absorption efficiencies and backscattering fractions. When measured data were not available due to instrumental detection limits, we extended the measured data with the Angstrom exponent relationship on the ultraviolet side, and a linear relationship on the visible side. The linear extrapolation is not based on physical reasoning, but affects the forcing very little.

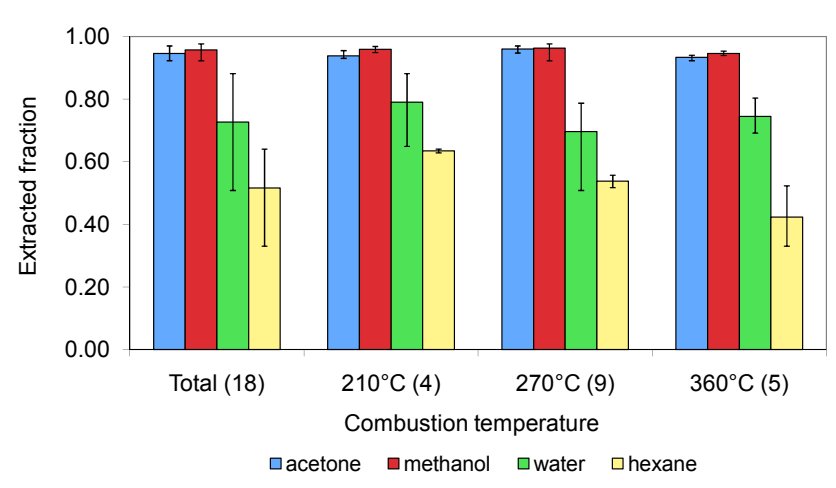

Fig. 4. Fraction of total OC extracted by different solvents. The numbers in the parentheses indicate the number of samples analyzed at each temperature. Methanol and water extraction were performed for all 18 samples, number of samples extracted by acetone and hexane: total: acetone (14), hexane $(6) ; 210^{\circ} \mathrm{C}$ : acetone (4), hexane (2); $270^{\circ} \mathrm{C}$ : acetone $(5)$, hexane $(2) ; 360^{\circ} \mathrm{C}$ : acetone (4), hexane (3).

\section{Results}

\subsection{Absorption by extracts in different organic solvents}

Figure 4 illustrates the average fraction of OC extracted by four solvents. For every sample, the amount of OC extracted by solvents is acetone $\approx$ methanol $>$ water $>$ hexane. Acetone and methanol extract almost all the OC, from $92 \%$ to $98 \%$. The fraction extracted by water and hexane varies from $51 \%$ to $88 \%$ with an average of $73 \%$ for water, and from $33 \%$ to $64 \%$ for hexane with an average of $52 \%$. Our results for water-soluble fraction are consistent with highly variable previous results: $40-99 \%$ reported by Novakov and Corrigan (1996) for smoldering combustion, and $41-74 \%$ observed by Graham et al. (2002) in biomass burning aerosols. Because of the high extractable fraction (greater than $92 \%$, for these samples), we consider absorption by methanol extracts to represent the behavior of total OC.

Figure 4 also shows extracted fractions at different generation temperatures. The OC fraction extracted by acetone, methanol and water does not change much with temperature. However, the fraction extracted by hexane decreases when generation temperature increases $(p=0.06)$; average fractions are $63 \%, 54 \%$ and $42 \%$ at $210^{\circ} \mathrm{C}, 270^{\circ} \mathrm{C}$ and $360^{\circ} \mathrm{C}$ respectively. OC from oak has an $11 \%$ higher fraction of watersoluble substances than from pine $(p=0.04)$, not separated in Fig. 4). No obvious trend of extractable fraction with wood size was found for methanol and acetone. However, water usually extracts a higher fraction of OC for samples from smaller wood.

Absorption per mass $(\alpha / \rho)$ is shown in Fig. 5 for sample generated from pine $\_$at $360^{\circ} \mathrm{C}$. Results from other wood types and sizes have similar trends but different values. For all samples, $\alpha / \rho$ values of methanol and acetone extracts are 
Table 2. Ratios of absorbance A and absorption per mass $\alpha / \rho$ between water extracts and methanol extracts for pine_M samples generated at $210^{\circ} \mathrm{C}, 270^{\circ} \mathrm{C}$ and $360^{\circ} \mathrm{C}$. (data are not available at $380 \mathrm{~nm}$ for $210^{\circ} \mathrm{C}$ and $270^{\circ} \mathrm{C}$ samples, because at $380 \mathrm{~nm}$ absorbance A is greater than 1).

\begin{tabular}{ccccccccc}
\hline & \multicolumn{3}{c}{ Ratio of $A$ (water/methanol) } & \multicolumn{4}{c}{ Ratio of $\alpha / \rho$ (water/methanol) } \\
& $380 \mathrm{~nm}$ & $400 \mathrm{~nm}$ & $450 \mathrm{~nm}$ & $500 \mathrm{~nm}$ & $380 \mathrm{~nm}$ & $400 \mathrm{~nm}$ & $450 \mathrm{~nm}$ & $500 \mathrm{~nm}$ \\
\hline $210^{\circ} \mathrm{C}$ & - & 0.63 & 0.44 & 0.38 & - & 0.70 & 0.48 & 0.42 \\
$270^{\circ} \mathrm{C}$ & - & 0.29 & 0.17 & 0.14 & - & 0.43 & 0.25 & 0.21 \\
$360^{\circ} \mathrm{C}$ & 0.25 & 0.19 & 0.13 & 0.14 & 0.32 & 0.24 & 0.17 & 0.18 \\
\hline
\end{tabular}

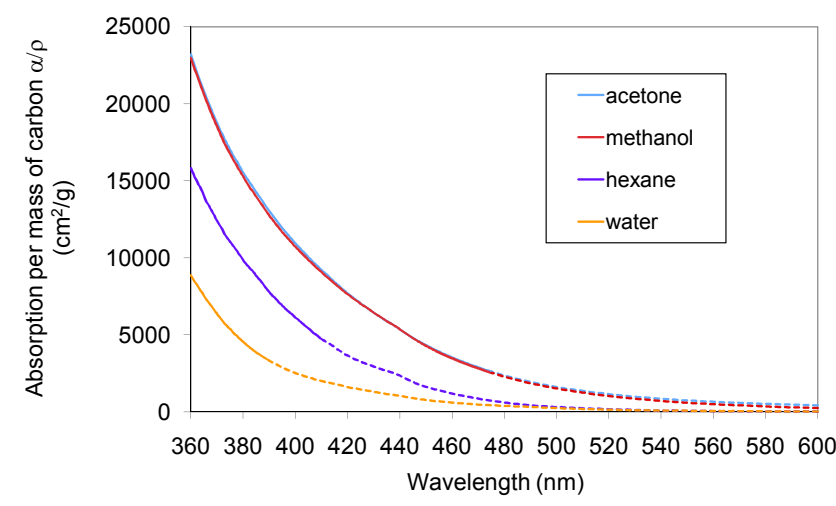

Fig. 5. Typical absorption spectrum for pine $\mathrm{L}$ generated at $360^{\circ} \mathrm{C}$. (Dashed lines indicate data below the instrument detection limit).

higher than those of water and hexane extracts. All the extracts appeared yellow, with absorption both at UV and visible ranges, and increasing absorption with decreasing wavelength. Brown to yellowish organic carbon was also observed from smoldering combustion by Patterson and McMahon (1984) and from coal combustion by Bond (2001).

Methanol and acetone extracts have the same $\alpha / \rho$ (absorption per mass) within measurement error. Kirchstetter et al. (2004) thought that OC not soluble in acetone might contribute some amount of absorption, but their samples were not pure OC. In our samples, most OC is soluble in acetone and no colored residue is observed.

Light absorption by organic carbon soluble in water and hexane is always smaller than that dissolved in methanol and acetone. Table 2 compares water extracts and methanol extracts for one size pine wood (pine_M). Other samples have similar trends. First, we compare total absorbance (A); this ratio indicates how much of the total absorption is extracted in water. The contribution of water-soluble $\mathrm{OC}$ is greater at shorter wavelengths, and this relationship is monotonic. Absorption per mass $(\alpha / \rho$ indicates the light-absorbing nature of the OC in different extracts. Normalized absorption for water-soluble OC is $76 \%$ lower than that for total OC at $400 \mathrm{~nm}$ for sample generated at $360^{\circ} \mathrm{C}$, although this comparison varies with wavelengths and generation conditions, which means that water-soluble OC is much less light absorbing than the total OC. In the comparison of $\alpha / \rho$, watersoluble OC contributes less as temperatures increase.

Absorption of hexane extracts, which should contain nonpolar OC, was also lower than that of methanol extract. For $210^{\circ} \mathrm{C}$ samples, $\alpha / \rho$ of hexane extracts was smaller or equal to that of water extract. When generation temperature increased, $\alpha / \rho$ of the hexane extracts also increased, and became greater than that of water extract, but still lower than that of methanol extract (e.g., averaged approximate $65 \%$ for oak_M_360).

In sections that follow, we will investigate the effect of temperature and wood characteristics. For these discussions, we will use methanol extracts since they represent the total carbon, and water soluble OC since it is important for hygroscopic properties of OC.

The $\alpha / \rho$ values presented here imply that the absorption of the methanol extracts comes from at least two types of OC: a less-absorbing, water-soluble OC, and a water-insoluble OC which has even higher absorption than the methanol extracts. In order to confirm this hypothesis, sequential extraction tests were conducted for two samples (oak_M_270, oak_L_360). A punch of filter was first extracted by water using the method described in Sect. 2.3, and the residual filter was extracted again by methanol after drying. Figure 6 shows spectra for one of these samples; the other produced similar results. OC extracted by methanol after water extraction was $18 \%$ of the total OC, but this small portion contributed $35-45 \%$ of the total absorbance, or 1-3 times that of the water extract, depending on the wavelength. Therefore, $\alpha / \rho$ or this fraction of OC was much higher than those of methanol and water extracts. By performing another water-hexane sequential extraction, we found that the residual after water extraction was partially soluble in hexane $(60 \%)$, while the remaining $40 \%$ could be extracted only by methanol. Moreover, the waterinsoluble but hexane-soluble part accounted for only $6 \%$ of the total absorbance. Therefore, we believe that the strongly light absorbing components are only extractable in methanol (not in either water or hexane).

The chosen solvent may affect absorption of some materials (Reichardt, 2003). To investigate whether this could affect our comparison, we vacuum-dried material extracted 

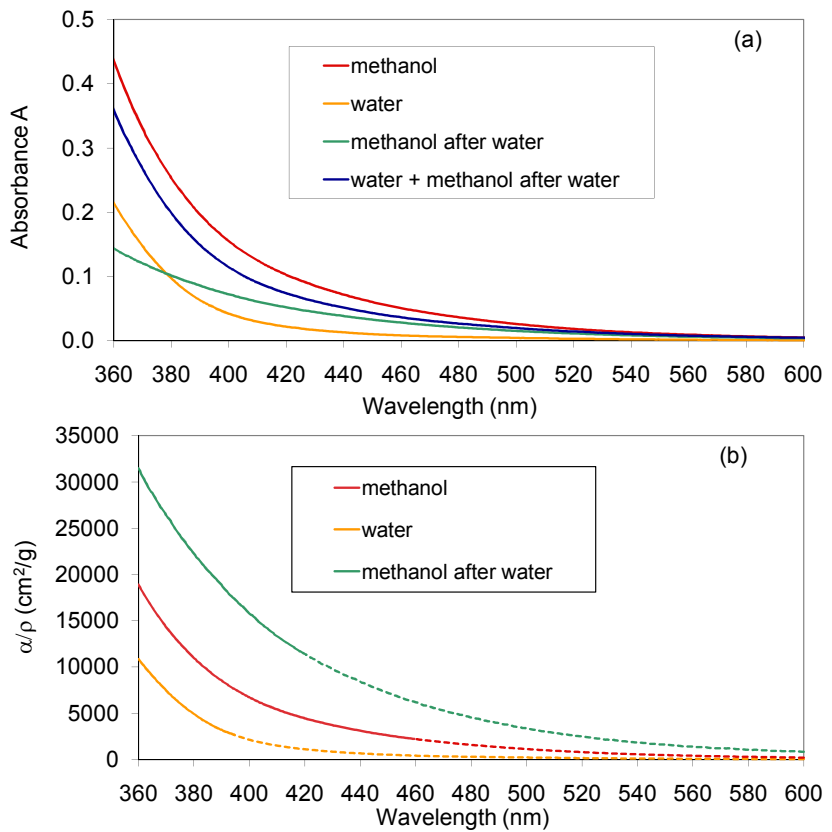

Fig. 6. (a) Spectra of absorbance and (b) absorption per mass for sample oak_M_270, of methanol extract, water extract, and methanol extract after water extraction. Note that there is no "water+methanol after water" curve in figure (b) because the normalized absorption (i.e. absorption per mass of carbon) is not additive, while absorbance is.

with methanol and redissolved the materials in water. 5\% methanol was added with the water to aid dissolution. The visible absorption was about $10-20 \%$ higher in water, so the finding that methanol-soluble material has higher absorption is valid regardless of solvent. In this paper, we provide the absorption data from methanol extracts without correction for this solvent effect.

\subsection{Effect of pyrolysis temperature}

In this paper, we investigated three different pyrolysis temperatures: $210^{\circ} \mathrm{C}, 270^{\circ} \mathrm{C}$ and $360^{\circ} \mathrm{C}$. Actual temperature varied $20^{\circ} \mathrm{C}$ from the nominal temperatures. Figure 7 shows the change in $\alpha / \rho$ with temperature for oak_M; pine and other wood sizes exhibited similar trends. For medium-sized wood, an increase from $210^{\circ} \mathrm{C}$ to $360^{\circ} \mathrm{C}$ results in a considerable increase of $\alpha / \rho$, approximately a factor of 9 for pine_M (averaged from $390 \mathrm{~nm}$ to $470 \mathrm{~nm}$ ) and 7 times for oak_M (averaged from $390 \mathrm{~nm}$ to $460 \mathrm{~nm}$ ). For large wood, a slight difference was observed between $210^{\circ} \mathrm{C}$ and $270^{\circ} \mathrm{C}$ samples, while samples at $360^{\circ} \mathrm{C}$ have much higher $\alpha / \rho$ values (not shown in Fig. 7). For $\alpha / \rho$ values for WSOC followed the same temperature dependent trends as total OC, but the absolute values of $\alpha / \rho$ were lower. In summary, when we increased pyrolysis temperature, $\alpha / \rho$ increased.

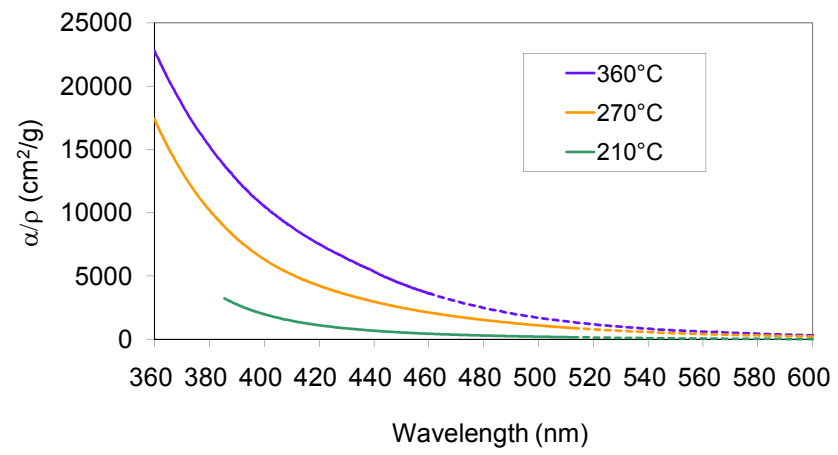

Fig. 7. Generation temperature dependence of absorption per mass $(\alpha / \rho)$ of methanol extracts (medium size oak wood).
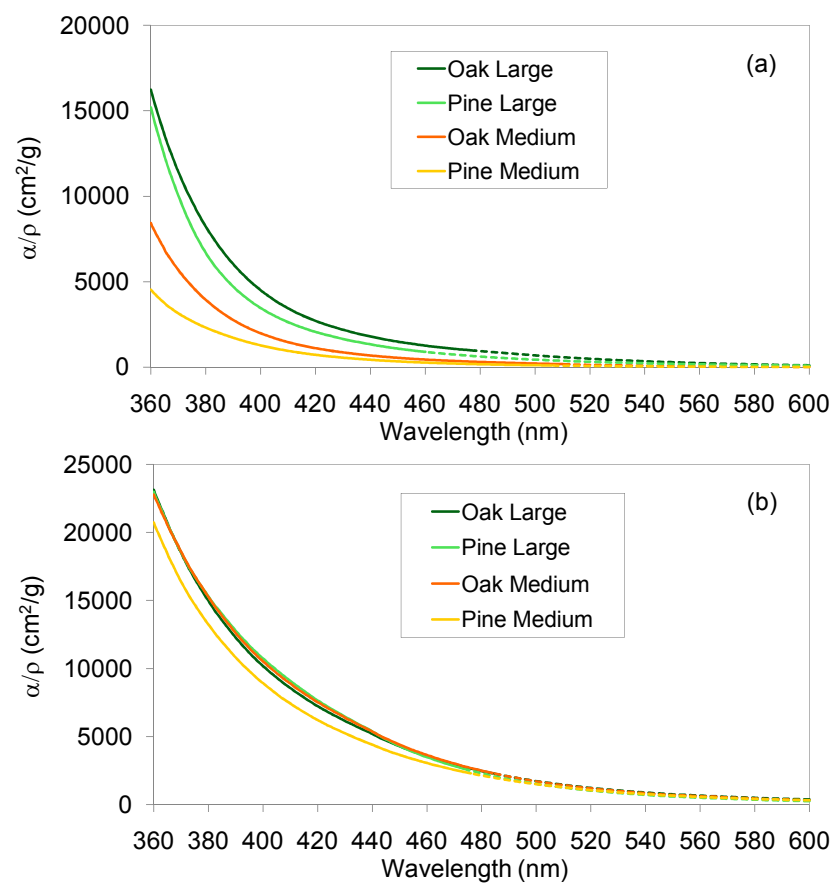

Fig. 8. Effect of wood type and size on absorption per mass $(\alpha / \rho)$ of methanol extracts. (a) $210^{\circ} \mathrm{C}$, (b) $360^{\circ} \mathrm{C}$ (note the scale change for two figures).

\subsection{Effect of wood type}

Figure 8 illustrates the variation of $\alpha / \rho$ values for methanol extracts with varying wood type and size, when temperature is held constant. At $210^{\circ} \mathrm{C}$, wood size and type affect the absorption of $\mathrm{OC}$ generated, while at high temperature $\left(360^{\circ} \mathrm{C}\right)$, the discrepancy is within the uncertainty range. Results at $270{ }^{\circ} \mathrm{C}$ are similar to those at $210^{\circ} \mathrm{C}$.

At low temperature, OC generated from pyrolysis of oak has higher absorption per mass than that from pyrolysis of pine. At $210^{\circ} \mathrm{C}$, the ratio between the two is 1.3 for large size and 1.6 for medium size averaged over $380 \mathrm{~nm}$ to $450 \mathrm{~nm}$. No significant difference was observed for samples generated by 


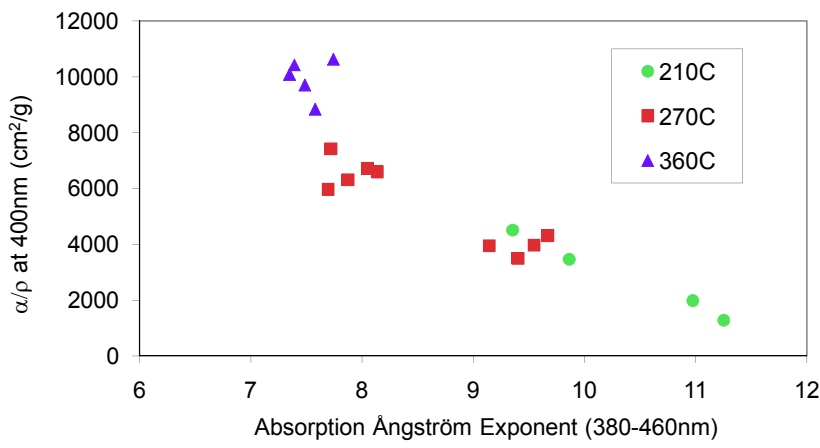

Fig. 9. $\AA_{\text {ap }}$ (from $380 \mathrm{~nm}$ to $460 \mathrm{~nm}$ ) vs. $\alpha / \rho$ at $400 \mathrm{~nm}$ of methanol extracts.

small size at $270{ }^{\circ} \mathrm{C}$. Since all other variables are the same, this discrepancy must be caused by a difference in wood type, and many such differences have been reported (Rogge et al., 1998; McDonald et al., 2000). Schauer et al. (2001) reported higher resin acids and substituted guaiacol emissions in pine combustion than in oak combustion, while substituted syringol compounds absent from pine combustion were found in oak combustion.

Despite the differences resulting from wood type, the larger difference is caused by generation temperature.

\subsection{Effect of wood size}

During wood pyrolysis, devolatilizing material travels along the wood grain in the absence of fissures and eventually escapes to the ambient air. Thus, the length along the grain governs the residence time of OC precursors inside the wood, and that residence time is larger in longer wood. On the other hand, the smallest cross-sectional area governs the rate of heat transfer into the wood, so medium and large wood are heated at approximately the same rates. In our study, $\mathrm{M}$ wood is a cube, and $\mathrm{L}$ wood has the same cross-section but is three times longer along the grain. $\mathrm{S}$ wood has the same length along the grain as $\mathrm{M}$ wood, but its cross-section is three times smaller. Figure 8 shows the dependence of $\alpha / \rho$ on wood size at different temperatures. For samples at lower temperatures, larger wood results in a higher absorption. We hypothesize that the longer residence time in the large wood allows polymerization which results in greater absorption per mass. At higher temperatures, that polymerization takes place even without the increased residence time.

In summary, our results show that absorption change is generally monotonic across the spectrum. If absorption increases, an increase occurs at all wavelengths, although the fractional change may not be the same across the spectrum. Increasing wood temperature leads to higher absorption. We hypothesize that this results from polymerization of the volatile matter before it exits the wood. Wood type has a smaller effect on absorption. Pine emissions have lower absorption than oak at the intermediate temperature, but at the higher temperature the absorption is identical. We suggest that similar transitions lead to thermal decomposition of wood, that one of these includes polymerization and that it occurs at a lower temperature in oak than in pine. The reactions that increase absorption are temperature-dependent, but residence time within the wood - which we alter by changing wood size - can make up for temperature, to some extent.

\subsection{Absorption Ångström exponent $\left(\AA_{\text {ap }}\right)$}

It has become accepted that $\mathrm{OC}$ absorption has stronger spectral dependence than that of BC (Patterson and McMahon, 1984; Bond, 2001; Kirchstetter et al., 2004; Schnaiter et al., 2006). In this work, values of $\AA_{\text {ap }}$ of methanol extracts, ranging from 6.9 to 11.4 , are shown in Table 1 and Fig. $9\left(R^{2}\right.$ ranges from 0.989 to 1.000). This is much higher than the values reported by Kirchstetter et al. (2004) for mixed black and organic carbon in biomass smoke aerosol, but similar to that reported by Schnaiter et al. (2006) for organic carbon formed in propane combustion with $\mathrm{C} / \mathrm{O}$ ratio of 0.61 .

$\AA_{\text {ap }}$ tends to decrease when generation temperature increases. $\AA_{\mathrm{ap}}$ of samples from pine smoldering is slightly, but not significantly, higher than that from oak. We can infer that higher $\AA_{\text {ap }}$ values are associated with weakly absorbing particles, which is consistent with real-time results in Roden et al. (2006). Using a dividing point of $400 \mathrm{~nm}$, we also calculate $\AA_{\text {ap }}$ for the ultraviolet and visible ranges separately. $\AA_{\text {ap }}$ at UV range is $0.95-1.3$ times of that at the whole UVvis range, from 6.6 to 14.3. For all but the samples by large wood at $360^{\circ} \mathrm{C}, \AA_{\text {ap }}$ is higher in the UV range.

We also calculated $\AA_{\text {ap }}$ of water extracts in the valid wavelength range (Table 1). Because of the lower absorbance of water extracts, for some samples, data were only valid in the UV range $(\lambda<400 \mathrm{~nm})$. Water extracts had much higher $\AA_{\text {ap }}$ than methanol extracts, ranging from 8.6 to 17.8 , although they exhibited similar dependence on wood size and temperature as methanol extracts. Compared with other samples, 4 samples generated at $360^{\circ} \mathrm{C}$ showed much lower $\AA_{\text {ap }}$ for water extracts.

\section{Discussion}

\subsection{Nature of light absorbing $\mathrm{OC}$}

We suggest the light absorbing OC in our samples is large molecular weight PAHs and oxygenated species which are formed through polymerization of small molecules present in the wood. Sun et al. (2007) discussed two kinds of organic carbon: a water-soluble organic mixture with some UV-visible absorption (Havers et al., 1998; Hoffer et al., 2006), and a water-insoluble organic carbon with higher absorption. Kirchstetter et al. (2004) and Schnaiter et al. (2006) provided such data for biomass burning and propane, respectively. 
Our results lend further support to this hypothesis. Although water-soluble organic carbon from wood combustion absorbs some visible light, a large fraction of absorption is caused by organic carbon that is not water-soluble but is extractable by methanol or acetone. Figure $10 \mathrm{com}-$ pares our results for the sequentially-extracted filters with the data tabulated by Sun et al. (2007). Ranges for watersoluble aerosols are marked "water-soluble minimum and water-soluble maximum" and "water-insoluble". The UV absorption of water-soluble OC lies between the ranges provided by Sun et al. (2007), while the visible absorption of that $\mathrm{OC}$ is lower than the minimum values tabulated in that work. Our samples were collected at the source, while the other tabulation examined atmospheric aerosol. Water-solubility might develop after oxidation in the atmosphere. Our data confirm that water-insoluble, more-absorbing OC exists, but our measured absorption is not as strong as that suggested by other measurements.

Large molecular PAHs (Kilbane II, 1998; Stovall et al., 2005) might be candidate compounds to represent the moreabsorbing OC, but those would be extractable in hexane. We hypothesize that the higher absorption comes from large, polar molecules which contain conjugated aromatic rings similar to PAHs, but that these rings are also directly attached to polar functional groups such as oxygen or nitrogen. Such complex molecules have been widely reported as products from biomass combustion at both flaming and smoldering conditions (e.g., Evans and Milne, 1986; Rogge et al., 1998; Schauer et al., 2001; Fitzpatrick et al., 2007; Weimer et al., 2008). Compared to small organic compounds, these molecules have more aromatic rings, (i.e. a higher degree of conjugation), which makes the absorption increase and shift to longer wavelengths (Apicella et al., 2004). Quinoid compounds are strong candidates for such compounds (Del Vecchio and Blough, 2004; Sun et al., 2007). PAH compounds were hexane-extractable while quinones could not be extracted by hexane but only by methanol (Xia et al., 2004; Shima et al., 2006). These substances might be detected in methods designed to isolate humic-like substances (HULIS; Graber and Rudich, 2006).

These complex molecules are formed by polymerization of the low molecular weight fragments during wood pyrolysis. Increased temperature enhances this polymerization, forming larger molecules with higher absorption per mass. Evans and Milne (1986) reported the formation of more polynuclear aromatics with increasing temperature. Oxygenated PAHs increased with temperature during the combustion of pine wood (Fitzpatrick et al., 2007).

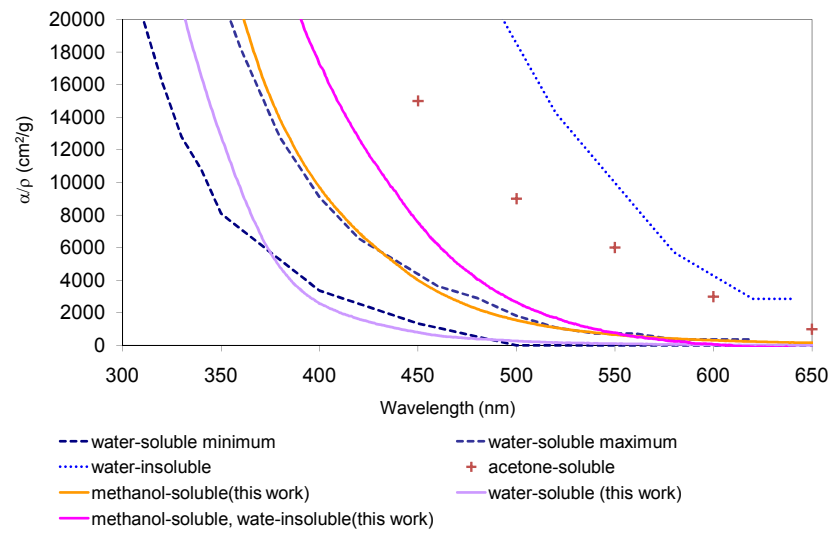

Fig. 10. Comparison with other results, generation condition: oak_L_360. Range for water-soluble aerosol, and an estimate for water-insoluble aerosol, are taken from Sun et al. (2007). "Acetonesoluble" is taken from Kirchstetter et al. (2004).

\subsection{Semivolatile organic carbon contribution}

Earlier, we commented that semivolatile organic carbon would increase the filter loading of carbon, and that this would decrease apparent values of $\alpha / \rho$. Until this point, we have given values of $\alpha / \rho$ for the combined semi- and nonvolatile organic carbon, and this was sufficient to discuss comparisons between pyrolysis conditions. Immediately following the present discussion, we will provide data suitable for radiative-transfer models. For this purpose, SVOC should be separated from NVOC.

As discussed in Sect. 2.5.2, we estimate the contribution of SVOC mass and absorption by heating filters in the OC/EC analyzer at $170^{\circ} \mathrm{C}$. This temperature roughly reproduces atmospheric partitioning but does not cause charring of OC. New samples were generated at all three pyrolysis temperatures, with the aim of determining the fraction of absorbance and OC mass contributed by NVOC. We analyzed OC concentration and bulk liquid absorbance for both original filters (TOC) and heated filters (NVOC). The difference between these two is the contribution of SVOC.

Loss of UV absorbance from the heated filters indicates that SVOC partially contributes to UV light absorption. Increased absorbance (10-30\%) in the visible range was observed. For samples generated at moderate and high temperatures, NVOC contributes to $80-90 \%$ absorbance at $360 \mathrm{~nm}$, while for the samples generated at low temperature, NVOC contributes only $60 \%$ of the total absorbance. Measurement uncertainty cannot account for this difference. The removed SVOC does contribute to the UV light absorption, and we need to account for this effect when estimating the absorption of NVOC. Increased absorbance in the visible range could be due to the chemical changes of organic carbon when heated. Since the absorbance for the heated filter was not lower than that of the original filter, we suggest that SVOC does not 


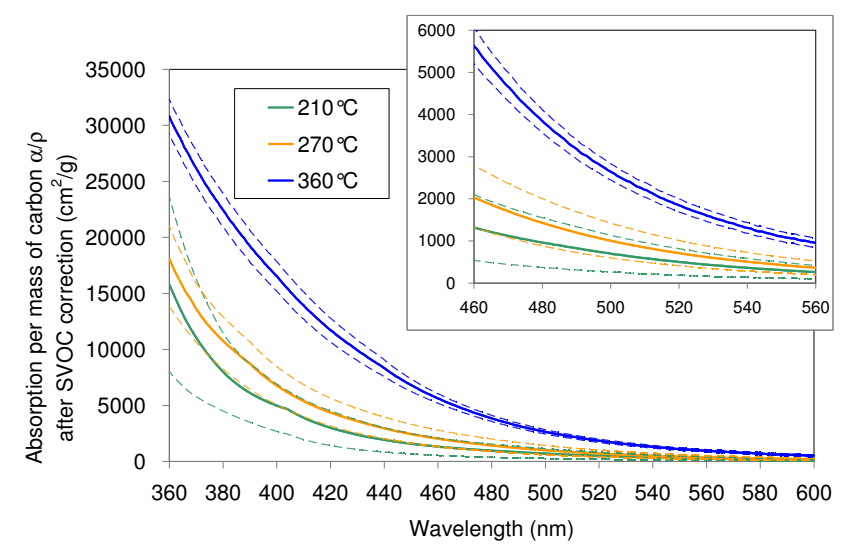

Fig. 11. Averaged absorption per mass of carbon $\alpha / \rho$ after correction for SVOC. Dashed lines with the same color indicate upper and lower range.

contribute to the visible absorption, although this question requires further study.

We use the amount of $\mathrm{OC}$ retained after $170^{\circ} \mathrm{C}$ heating to indicate the mass of NVOC. The averaged mass ratio of NVOC / TOC is $0.56,0.69$ and 0.61 for samples generated at $210^{\circ} \mathrm{C}, 270^{\circ} \mathrm{C}$ and $360^{\circ} \mathrm{C}$ respectively.

We adjusted the absorption per mass at UV wavelengths using the temperature-specific results for NVOC absorbance and carbon, thereby correcting the value of $\alpha / \rho$. This is our best guess of values to be used for OC properties in radiativetransfer models. Figure 11 shows the average and standard deviation of $\alpha / \rho$ at each generation temperature. The dependence of absorption on generation temperature is apparent even when variation due to wood types and size is included. Samples generated at lower temperatures have a larger variation due to the effect of wood size and wood type, while at high temperature wood size and wood type have little effect on absorption. The ratio between hightemperature and low-temperature absorption is about 4 at visible wavelengths $(400-550 \mathrm{~nm})$ and somewhat lower at ultraviolet wavelengths.

The SVOC correction will not change our previous conclusion that methanol-extractable material has higher absorption than water-extractable material. To negate this conclusion, water-extractable SVOC would have to contribute $60 \%$ of the total OC, which was not observed. Furthermore, as a general rule, lower volatility aerosol has lower water solubility (Schwarzenbach et al., 2003), which means that water actually extracts less SVOC than methanol does.

\subsection{Radiative implications}

As discussed in Sect. 2.8, we use a simple model to provide a first estimate of these absorbing particles' climatic impact. We use this model with material generated at both high and low temperatures, as well as non-absorbing particles (imagi-
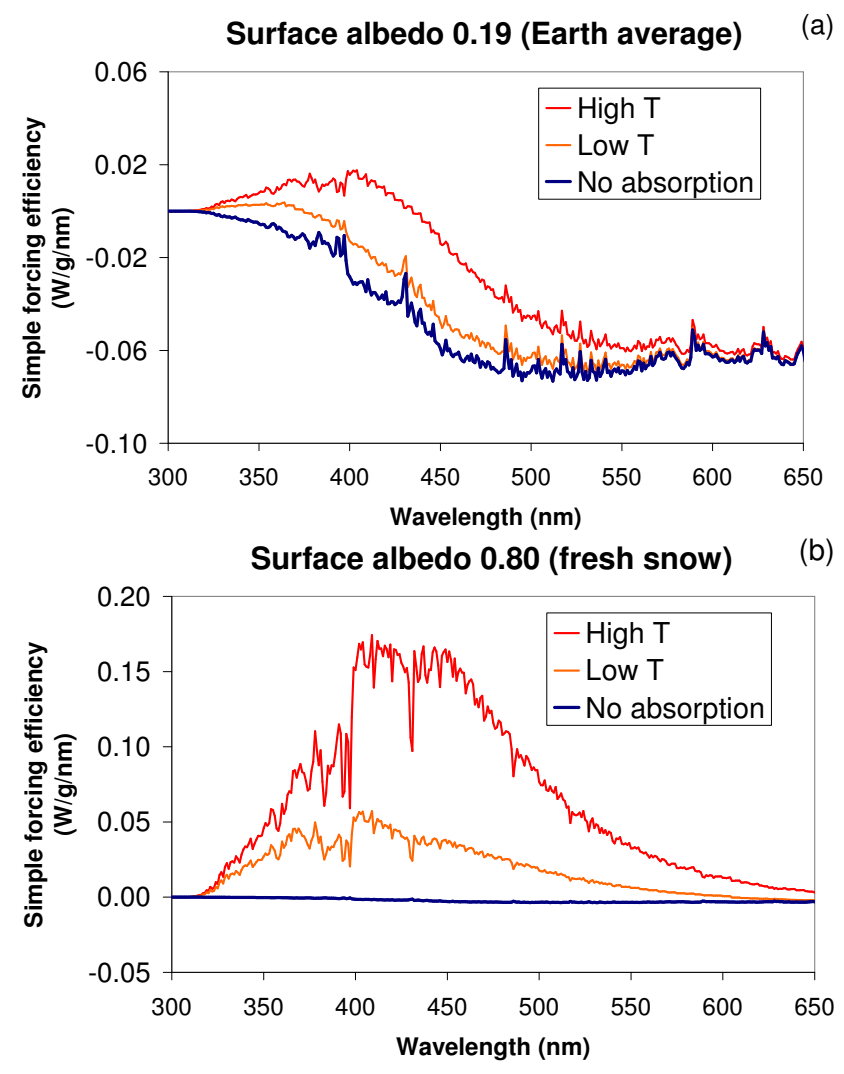

Fig. 12. Simple forcing efficiency of particles above an average albedo (a) and snow (b). Integrated forcing for average and snow albedo, respectively: High $T,-12$ and $23 \mathrm{~W} / \mathrm{g}$ Low $T,-16$ and $6.3 \mathrm{~W} / \mathrm{g}$; no absorption: -18 and $-0.92 \mathrm{~W} / \mathrm{g}$.

nary refractive index 0.0001). In our model, real refractive index is held constant at 1.55 , and surface albedo is held constant at the values shown in the figure. Mie simulations assumed a count median diameter of $150 \mathrm{~nm}$ and a geometric standard deviation of 1.5 , similar to observations of fresh aerosol in our laboratory.

Figure 12a shows forcing at each wavelength for a surface albedo of 0.19 . Integrated forcing from 300 to $950 \mathrm{~nm}$ is $-12 \mathrm{~W} / \mathrm{g}$ for particles from high-temperature burning, $-16 \mathrm{~W} / \mathrm{g}$ for the low- $\mathrm{T}$ particles, and $-18 \mathrm{~W} / \mathrm{g}$ for nonabsorbing particles. All particles have net negative forcing. Our model does not include hygroscopicity, which increases particle size and negative forcing. Thus, our forcing efficiences are much lower than those in global climate models (about $-80 \mathrm{~W} / \mathrm{g}$, Schulz et al., 2006), and should be illustrative only. A full climate model would be necessary to determine the actual forcing caused by this absorption. Including absorption changes forcing efficiency by only a few percent, compared to the average from global climate models. Unless absorption by real ambient aerosol is higher than that measured here, representing it is probably not important for global average clear-sky forcing. 
Figure $12 \mathrm{~b}$ repeats the calculation for particles over a bright surface. Forcing integrated over the solar spectrum is $23 \mathrm{~W} / \mathrm{g}$ for the high-temperature particles, $6.3 \mathrm{~W} / \mathrm{g}$ for the low temperature particles; and $-0.92 \mathrm{~W} / \mathrm{g}$ for the particles with no absorption. The contribution of absorbing organic material could be important in energy balances over bright surfaces. Global average radiative forcing of absorbing OC, considering its location above and below clouds and relative to bright surfaces, should be assessed with a general circulation model.

\subsection{Effect of UV absorption on tropospheric photochemistry}

The absorption of UV light by OC may influence photolysisdriven chemistry in the troposphere. Although this is not a focus of our study, we briefly discuss the potential impact. Jacobson (1998) investigated the effect of absorbing aerosols on photolysis ratio coefficient and ozone mixing ratio with the GATORM model, by applying the refractive index of liquid nitrobenzene as a surrogate in model simulations. It was concluded that absorbing organic aerosols may cause the reduction in UV photolysis coefficients, resulting in up to $5-8 \%$ decrease in near-surface ozone mixing ratio during the Southern California Air Quality Study period. The UV absorption of OC obtained from our samples generated at $360{ }^{\circ} \mathrm{C}$ is lower than that in the Jacobson (1998) study by $30-40 \%$, depending on wavelength. It can be inferred that the significant UV absorption by total OC from wood pyrolysis could affect photolysis rates and thus ozone mixing ratio by a few percent.

\section{Summary}

We measured light absorption of organic carbon generated in a laboratory combustor at different temperatures, wood types, and wood sizes. We provide estimates for the absorption per mass of carbon contributed by NVOC at varying generation temperatures. The main points of this manuscript are summarized below.

- Solid-fuel combustion produces yellow or brown carbon. Absorption increases as wavelength decreases.

- Methanol extracts almost all of the total organic carbon, while the portion of water soluble organic carbon is 51$88 \%$ and depends on generation temperature.

- Water-soluble OC absorbs some light. However, a large fraction of the absorbing part is water-insoluble, but extractable by methanol, and this material has greater absorption per mass. We hypothesize that the high absorption comes from large containing both conjugated aromatic rings and functional groups.
- Increasing generation temperature and, possibly, longer residence time in the wood produce higher absorption. Wood type has a smaller effect on absorption.

Acknowledgements. This project is supported by the National Science Foundation's Atmospheric Chemistry Program under grant \#ATM-0349292 Program.

Edited by: V. F. McNeill

\section{References}

Andreae, M. O., Andreae, T. W., Annegarn, H., Beer, J., Cachier, H., Le Canut, P., Elbert, W., Maenhaut, W., Salma, I., Wienhold, F. G., and Zenker, T.: Airborne studies of aerosol emissions from savanna fires in southern Africa: 2. Aerosol chemical composition, J. Geophys. Res., 103, 32119-32128, 1998.

Andreae, M. O. and Gelencsér, A.: Black carbon or brown carbon? The nature of light-absorbing carbonaceous aerosols, Atmos. Chem. Phys., 6, 3131-3148, 2006, http://www.atmos-chem-phys.net/6/3131/2006/.

Anderson, T. L., Charlson, R. J., Schwartz, S. E., Knutti, R., Boucher, O., Rodhe, H., Heintzenberg, J.: Climate forcing by aerosols - a hazy picture, Science, 300, 1103-1104, 2003.

Antal Jr., M. J. and Varhegyi, G.: Cellulose pyrolysis kinetics: the current state of knowledge, Ind. Eng. Chem. Res., 34, 703-717, 1995.

Apicella, B., Alfe, M., Barbella, R., Tegrossi, A., and Ciajolo, A.: Aromatic structures of carbonaceous materials and soot inferred by spectroscopic analysis, Carbon, 42, 1583-1589, 2004.

Bergstrom, R. W., Pilewskie, P., Russell, P. B., Redemann, J., Bond, T. C., Quinn, P. K., and Sierau, B.: Spectral absorption properties of atmospheric aerosols, Atmos. Chem. Phys., 7, 5937-5943, 2007 , http://www.atmos-chem-phys.net/7/5937/2007/.

Bond, T. C.: Spectral dependence of visible light absorption by carbonaceous particles emitted from coal combustion, Geophys. Res. Lett., 28, 4075-4078, 2001.

Bond, T. C., Streets, D. G., Yarber, K. F., Nelson, S. M., Woo, J., and Klinont, Z.: A technology-based global inventory of black and organic carbon emissions from combustion, J. Geophys. Res., 109, D14203, doi:10.1029/2003JD003697, 2004.

Bond, T. C. and Bergstrom, R. W.: Light absorption by carbonaceous particles: an investigative review, Aerosol Sci. Technol., 40, 27-67, 2006.

Bryden, K. M., Ragland, K. W., and Rutland, C. J.: Modeling thermally thick pyrolysis of wood, Biomass Bioenerg., 22, 41-53, 2002.

Chung, S. H. and Seinfeld, J. H.: Global distribution and climate forcing of carbonaceous aerosols, J. Geophys. Res., 107(D19), 4407, doi:10.1029/2001JD001397, 2002.

Chylek, P. and Wong, J.: Effect of absorbing aerosol on global radiation budget, Geophys. Res. Lett., 22, 929-931, 1995.

Cooke, W. F., Liousse, C., Cachier, H., and Feichter, J.: Construction of a $1 \times 1$ fossil fuel emission data set for carbonaceous aerosol and implementation and radiative impact in the ECHAM4 model, J. Geophys. Res., 104, 22137-22162, 1999. 
Del Vecchio, R. and Blough, N. V.: On the origin of the optical properties of humic substances, Environ. Sci. Technol., 38, 3885-3891, 2004.

Donahue, N. M., Robinson, A. L., Stanier, C. O., and Pandis, S. N.: Coupled partitioning, dilution, and chemical aging of semivolatile organics, Environ. Sci. Technol., 40, 2635-2643, 2006.

Evans, R. J. and Milne, T. A.: Molecular characterization of the pyrolysis of biomass, 1. Fundamentals, Energy and Fuel, 1, 123137, 1986.

Ferek, R. J., Reid, J. S., Hobbs, P. V., Blake, D. R., and Liousse, C.: Emission factors of hydrocarbons, trace gases and particles from biomass burning in Brazil, J. Geophys. Res., 103, 32107-32118, 1998.

Fitzpatrick, E. M., Ross, A. B., Bates, J., Andrews, G., Jones, J. M., Phylaktou, H., Pourkashanian M., and Willams, A.: Emission of oxygenated species from the combustion of pine wood and its relation to soot formation, Process Saf. Environ. Protect., 85(B5), 430-440, 2007.

Gabriel, R., Mayol-Bracero, O. L., and Andreae, M. O.: Chemical characterization of submicron aerosol particles collected over the Indian Ocean, J. Geophys. Res., 107(D19), 8005, doi:10.1029/2000JD000034, 2002.

Graber, E. R. and Rudich, Y.: Atmospheric HULIS: How humiclike are they? A comprehensive and critical review, Atmos. Chem. Phys., 6, 729-753, 2006,

http://www.atmos-chem-phys.net/6/729/2006/.

Graham, B., Mayol-Bracero, O. L., Guyon, P., Roberts, G. C., Decesari, S., Facchini, M. C., Artaxo, P., Maenhaut, W., Koll, P., and Andreae, M. O.: Water-soluble organic compounds in biomass burning aerosols over Amazonia 1. Characterization by NMR and GC-MS, J. Geophys. Res., 107(D20), 8047, doi:10.1029/2001JD000336, 2002.

Havers, A., Burba, P., Lambert, J., and Klockow, D.: Spectroscopic characterization of humic-like substances in airborne particulate matter, J. Atmos. Chem., 29, 45-54, 1998.

He, K., Yang, F., Ma, Y., Zhang, Q., Yao, X., Chan, C., Cadle, S., Chan, T., and Mulawa, P.: The characteristics of $\mathrm{PM}_{2.5}$ in Beijing, China, Atmos. Environ., 35, 4959-4970, 2001.

Hoffer, A., Gelencsér, A., Guyon, P., Kiss, G., Schmid, O., Frank, G. P., Artaxo, P., and Andreae, M. O.: Optical properties of humic-like substances (HULIS) in biomass-burning aerosols, Atmos. Chem. Phys., 6, 3563-3570, 2006,

http://www.atmos-chem-phys.net/6/3563/2006/.

Husain, L., Dutkiewicz, V. A., Khan, A. J., Chin, M., and Ghauri, B. M.: Characterization of carbonaceous aerosols in urban air, Atmos. Envrion., 41, 6872-6883, 2007.

Intergovernmental Panel on Climate Change (IPCC): IPCC Fourth Assessment Report, Working Group I Report "The Physical Science Basis", http://www.ipcc.ch, 2007.

Jacobson, M. Z.: Studying the effects of aerosols on vertical photolysis rate coefficient and temperature profiles over and urban airshed, J. Geophys. Res., 103, 10593-10604, 1998.

Johnson, K. S., de Foy, B., Zuberi, B., Molina, L. T., Molina, M. J., Xie, Y., Laskin, A., and Shutthanandan, V.: Aerosol composition and source apportionment in the Mexico City Metropolitan Area with PIXE/PESA/STIM and multivariate analysis, Atmos. Chem. Phys., 6, 4591-4600, 2006,

http://www.atmos-chem-phys.net/6/4591/2006/.
Kilbane II, J. J.: Extractability and subsequent biodegreadation of PAHs from contaminated soil, Water, Air, Soil Pollut., 104, 285304, 1998.

Kirchstetter, T. W., Corrigan, C. E., and Novakov, T.: Laboratory and field investigation of the adsorption of gaseous organic compounds onto quartz filters, Atmos. Environ., 35, 1663-1671, 2001

Kirchstetter, T. W., Novakov, T., and Hobbs, P. V.: Evidence that the spectral dependence of light absorption by aerosols is affected by organic carbon, J. Geophys. Res., 109, D21208, doi:10.1029/2004JD004999, 2004.

Krecl, P., Ström, J., and Johansson, C.: Carbon content of atmospheric aerosols in a residential area during the wood combustion season in Sweden, Atmos. Environ., 41, 6974-6985, 2007.

Liousse, C., Penner, J. E., Chuang, C., Walton, J. J., Eddleman, H., and Cachier, H.: A global three-dimensional model study of carbonaceous aerosols, J. Geophys. Res., 101, 19411-19432, 1996.

Mader, B. T., Flagan, R. C., and Seinfeld, J. H.: Airborne measurements of atmospheric carbonaceous aerosols during ACE-Asia, J. Geophys. Res., 107(D23), 4704, doi:10.1029/2002JD002221, 2002.

McComiskey, A., Schwartz, S. E., Schmid, B., Guan, H., Lewis, E. R., Ricchiazzi, P., and Ogren, J. A.: Direct aerosol forcing: Calculation from observables and sensitivities to inputs, J. Geophys. Res., 113, D09202, doi:10.1029/2007JD009170, 2008.

McDonald, J. D., Zielinska, B., Fujita, E. M., Sagebiel, J. C., Chow, J. C., and Watson, J. G.: Fine particle and gaseous emission rates from residential wood combustion, Environ. Sci. Technol., 34, 2080-2091, 2000.

McDow, S. R. and Huntzicker, J. J.: Vapor adsorption artifact in the sampling of organic aerosol: face velocity effects, Atmos. Environ., 24A, 2563-2571, 1990.

Meng, Z. Y., Jiang, X. M., Yan, P., Lin, W. L., Zhang, H. D., and Wang, Y.: Characteristics and sources of $\mathrm{PM}_{2.5}$ and carbonaceous species during winter in Taiyuan, China, Atmos. Environ., 41, 6901-6908, 2007.

Molnár, A., Mészáros, E., Hansson, H. C., Karlsson, H., Gelencsér, A., Kiss, G., and Krivácsy, Z.: The importance of organic and elemental carbon in the fine atmospheric aerosol particles, Atmos. Envrion., 33, 2745-2750, 1999.

Murphy, D. M., Cziczo, D. J., Froyd, K. D., Hudson, P. K., Matthew, B. M., Middlebrook, A. M., Peltier, R. E., Sullivan, A., Thomson, D. S., and Weber, R. J.: Single-particle mass spectrometry of tropospheric aerosol particles, J. Geophys. Res., 111, D23S32, doi:10.1029/2006JD007340, 2006.

Novakov, T. and Corrigan, C. E.: Cloud condensation nucleus activity of the organic component of biomass smoke particles, Geophys. Res. Lett., 23, 2141-2144, 1996.

Patterson, E. M. and McMahon, C. K.: Absorption characteristics of forest fire particulate matter, Atmos. Environ., 11, 2541-2551, 1984.

Polidori, A. P., Turpin, B. J., Davidson C. I., Rodenburg, L. A., and Maimone, F.: Organic $\mathrm{PM}_{2.5}$ : fractionation by polarity, FTIR spectroscopy, and OM/OC ratio for the Pittsburgh aerosol, Aerosol Sci. Technol., 42, 233-246, 2008.

Pöschl, U.: Aerosol particle analysis: challenges and progress, Anal. Bioanal. Chem., 375, 30-32, 2003.

Qin, Y. and Mitchell, R. M.: Characterisation of episodic aerosol 
types over the Australian continent, Atmos. Chem. Phys., 9, 1943-1956, 2009,

http://www.atmos-chem-phys.net/9/1943/2009/.

Quinn, P. K. and Bates, T. S.: North American, Asian, and Indian haze: Similar regional impacts on climate?, Geophys. Res. Lett., 30, 1555, doi:10.1029/2003GL016934, 2003.

Quinn, P. K. and Bates, T. S.: Regional aerosol properties: comparison of boundary layer measurements from ACE1, ACE2, Aerosols99, INDOEX, ACE Asia, TARFOX, and NEAQS, J. Geophys. Res., 110, D14202, doi:10.1029/2004JD004755, 2005.

Reichardt, C.: Solvents and solvent effects in organic chemistry, Wiley-VCH Verlag GmbH \& Co. KGaA, Weinheim, Germany, 2003.

Reid, J. S., Koppmann, R., Eck, T. F., and Eleuterio, D. P.: A review of biomass burning emissions part II: intensive physical properties of biomass burning particles, Atmos. Chem. Phys., 5, 799825,2005 ,

http://www.atmos-chem-phys.net/5/799/2005/.

Robinson, A. L., Donahue, N. M., Shrivastava, M. K., Weitkamp, E. A., Sage, A. M., Grieshop, A. P., Lane, T. E., Pierce, J. R., and Pandis, S. N.: Rethinking organic aerosols: semivolatile emissions and photochemical aging, Science, 315, 1259-1262, 2007.

Roden, C. A., Bond, T. C., Conway, S., and Pinel, A.: Emission Factors and real-time optical properties of particles emitted from traditional wood burning cookstoves, Environ. Sci. Technol., 40, 6750-6757, 2006.

Roden, C. A., Bond, T. C., Conway, S., Pinel, A., MacCarty, N., and Still, D.: Laboratory and field investigations of particulate and carbon monoxide emissions from traditional and improved cookstoves, Atmos. Environ., 43, 1170-1181, 2009.

Rogge, W. F., Hildemann, L. M., Mazurek, M. A., and Cass, G. R.: sources of fine organic aerosol, 9. Pine, oak, and synthetic log combustion in residential fireplaces, Environ. Sci. Technol., 32, 13-22, 1998.

Schauer, J. J., Kleeman, M. J., Cass, G. R., and Simoneit, B. R. T.: Measurement of emissions from air pollution sources, 3. C1-C29 organic compound from fireplace combustion of wood, Environ. Sci. Technol., 35, 1716-1728, 2001.

Schnaiter, M., Gimmler, M., Llamas, I., Linke, C., Jäger, C., and Mutschke, H.: Strong spectral dependence of light absorption by organic carbon particles formed by propane combustion, Atmos. Chem. Phys., 6, 2981-2990, 2006, http://www.atmos-chem-phys.net/6/2981/2006/.

Schulz, M., Textor, C., Kinne, S., Balkanski, Y., Bauer, S., Berntsen, T., Berglen, T., Boucher, O., Dentener, F., Guibert, S., Isaksen, I. S. A., Iversen, T., Koch, D., Kirkevåg, A., Liu, X., Montanaro, V., Myhre, G., Penner, J. E., Pitari, G., Reddy,
S., Seland, Ø., Stier, P., and Takemura, T.: Radiative forcing by aerosols as derived from the AeroCom present-day and pre-industrial simulations, Atmos. Chem. Phys., 6, 5225-5246, 2006,

http://www.atmos-chem-phys.net/6/5225/2006/.

Schwarzenbach, R. P., Gschwend, P. M., and Imboden, D. M.: Environmental organic chemistry, John Wiley \& Sons, Inc., New Jersey, USA, 2003.

Shafizadeh, F.: Introduction to pyrolysis of biomass, J. Anal. Appl. Pyrol., 3, 283-305, 1982.

Shima, H., Koike, E., Shinohara, R., and Kobayashi, T.: Oxidative ability and toxicity of n-hexane insoluble fraction of diesel exhaust particles, Toxicol. Sci., 91, 218-226, 2006.

Shrivastava, M. K., Lipsky, E. M., Stanier, C. O., and Robinson, A. L.: Modeling semivolatile organic aerosol mass emissions from combustion systems, Environ. Sci. Technol., 40, 26712677, 2006.

Stovall D. M., Hoover, K. R., Acree, J. W. E., and Abraham, M. H.: Solubility behavior of crystalline polycyclic aromatic hydrocarbons (PAHs): Prediction of fluorine solubilities in organic solvents with the Abraham solvation parameter model, Polycyclic Aromat. Compd., 25, 313-326, 2005.

Sun, H., Biedermann, L., and Bond, T. C.: Color of brown carbon: a model for ultraviolet and visible light absorption by organic carbon aerosol, Geophys. Res. Lett., 34, L17813, doi:10.1029/2007GL029797, 2007.

Turpin, B. J., Hering, S. V., and Huntzicker, J. J.: Investigation of organic aerosol sampling artifacts in the Los Angeles Basin, Atmos. Environ., 28, 3061-3071, 1994.

Turpin, B. J., Saxena, P., and Andrews, E.: Measuring and simulating particulate organics in the atmosphere: problems and prospects, Atmos. Environ., 34, 2983-3013, 2000.

Varga, B., Kiss, G., Ganszky, I., Gelencsér, A., and Krivácsy, Z.: Isolation of water-soluble organic matter from atmospheric aerosol, Talanta, 55, 561-572, 2001.

Weimer, S., Alfarra, M. R., Schreiber, D., Mohr, M., Prévôt, A. S. H., and Baltensperger, U.: Organic aerosol mass spectral signature from wood-burning emissions: influence of burning conditions and wood type, J. Geophys. Res., 113, D10304, doi:10.1029/2007JD009309, 2008.

Xia, T., Korge, P., Weiss, J. N., Li, N., Indira Venkatesen, M., Sioutas, C., and Nel, A.: Quinones and aromatic chemical compounds in particulate matter induce mitochondrial dysfunction: implications for ultrafine particle toxicity, Environ. Health Perspect., 112, 1347-1358, 2004. 